2011-04-01

\title{
Stochastic Hybrid Embodied CO2-eq Analysis: an Application to the Irish Apartment Building Sector
}

Adolf Acquaye

Technological University Dublin, adolf.acquaye@tudublin.ie

Aidan Duffy

Technological University Dublin, aidan.duffy@tudublin.ie

Biswajit Basu

Trinity College Dublin, basub@tcd.ie

Follow this and additional works at: https://arrow.tudublin.ie/dubenart

Part of the Applied Statistics Commons, Architectural Engineering Commons, Construction Engineering Commons, Environmental Design Commons, Environmental Indicators and Impact Assessment Commons, Environmental Monitoring Commons, Natural Resource Economics Commons, Natural Resources and Conservation Commons, Natural Resources Management and Policy Commons, Other Civil and Environmental Engineering Commons, Probability Commons, and the Sustainability Commons

\section{Recommended Citation}

Acquaye, A., Duffy, A \& Basu, B. (2011) Stochastic hybrid embodied C02-eq analysis: An application to the Irish apartment building sector. Energy and Buildings, vol.43, no.6, pp.1259-13-3. doi:10.1016/ j.enbuild.2011.01.006.

This Article is brought to you for free and open access by the Dublin Energy Lab at ARROW@TU Dublin. It has been accepted for inclusion in Articles by an authorized administrator of ARROW@TU Dublin. For more information, please contact arrow.admin@tudublin.ie, aisling.coyne@tudublin.ie, gerard.connolly@tudublin.ie. Funder: Department of Education, Ireland

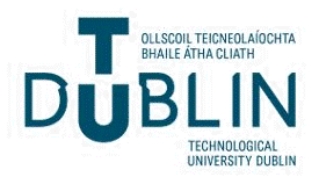




\section{AUTHOR QUERY FORM}

\begin{tabular}{|c|c|c|}
\hline 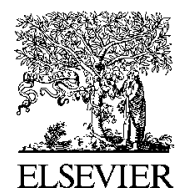 & Article Number: 3101 & $\begin{array}{l}\text { Please e-mail or fax your responses and any corrections to: } \\
\text { E-mail: corrections.esil@elsevier.thomsondigital.com } \\
\text { Fax: }+35361709272\end{array}$ \\
\hline
\end{tabular}

Dear Author,

Please check your proof carefully and mark all corrections at the appropriate place in the proof (e.g., by using on-screen annotation in the PDF file) or compile them in a separate list. To ensure fast publication of your paper please return your corrections within 48 hours.

For correction or revision of any artwork, please consult http://www.elsevier.com/artworkinstructions.

Any queries or remarks that have arisen during the processing of your manuscript are listed below and highlighted by flags in the proof. Click on the ' $Q$ ' link to go to the location in the proof.

\begin{tabular}{|c|c|}
\hline $\begin{array}{l}\text { Location in } \\
\text { article }\end{array}$ & $\begin{array}{l}\text { Query / Remark: click on the Q link to go } \\
\text { Please insert your reply or correction at the corresponding line in the proof }\end{array}$ \\
\hline $\begin{array}{l}\mathrm{Q} 1 \\
\frac{\mathrm{Q} 2}{\mathrm{Q} 3} \\
\frac{\mathrm{Q} 4}{\mathrm{Q} 5}\end{array}$ & $\begin{array}{l}\text { As per the style of the journal, abstract should not have more than } 200 \text { words. However, in this article, } \\
\text { abstract is having more than } 200 \text { words. Please check, and amend as necessary } \\
\text { "Lenzen et al. (2000)" has been changed to "Lenzen and Dey }(2000) \text { " in the sentence "This is because } \\
\text { Lenzen ... data is in the region of } 20 \% " \text {. Please check, and correct if necessary } y_{\lambda} \\
\text { As Refs. [13] and [36] were identical, the latter has been removed from the reference list and subsequent } \\
\text { references have been renumbered. } \\
\text { Please check the article title in Ref. [8], correct if necessary } \\
\text { Please check the presentation of Refs. [22-25, 28, 33], and correct if necessary, }\end{array}$ \\
\hline
\end{tabular}

Thank you for your assistance. 


\title{
Stochastic hybrid embodied $\mathrm{CO}_{2}$-eq analysis: An application to the Irish apartment building sector
}

\author{
Adolf A. Acquaye ${ }^{\mathrm{a}}$, Aidan P. Duffy ${ }^{\mathrm{a}, *}$, Biswajit Basu ${ }^{\mathrm{b}}$ \\ a School of Civil and Building Services Engineering and Dublin Energy Lab, Dublin Institute of Technology, Ireland \\ ${ }^{\mathrm{b}}$ Department of Civil, Structural and Environmental Engineering, Trinity College, Dublin 2, Ireland
}

\section{A R T I C L E I N F O}

\section{Article history:}

Received 8 March 2010

Received in revised form 6 January 2011

Accepted 12 January 2011

\section{Keywords:}

Hybrid embodied $\mathrm{CO}_{2}$-eq

Stochastic analysis

Construction sub-sector

Apartment buildings

Probabilistic and cumulative distributions

Monte Carlo analysis

\begin{abstract}
A B S T R A C T
The development of _embodied $\mathrm{CO}_{2}$-eq analysis has progressed significantly in recent years and has become a mainstream practice in many industries, as evidenced by, the development, of the ISO 14040 and 14044 life cycle assessment (LCA) standards. However, it is recognized that due to weaknesses in gathering data on product-related emissions, embodied $\mathrm{CO}_{2}$-eq values are probabilistic. This paper therefore presents a stochastic analysis of hybrid embodied $\mathrm{CO}_{2}-\mathrm{eq}$ in buildings to account for this weakness in traditional methods and, by way of example, applies it to an Irish construction-sector case study. Using seven apartment buildings, 70,000 results are simulated with Monte Carlo analysis and used to derive probabilistic and cumulative embodied $\mathrm{CO}_{2}$-eq intensity distributions for apartment buildings in Ireland. A Wakeby distribution with known statistical parameters and uncertainty was derived for the average embedied $\mathrm{CO}_{2}$ intensity of apartment buildings in Ireland. The mean hybrid embodied $\mathrm{CO}_{2}$-eq $\left(\mathrm{ECO}_{2}\right.$ eq)intensity Was estimated to be $1636 \mathrm{gCO}_{2}$-eq/€ with an uncertainty of $73 \mathrm{gCO}_{2}$-eq/€. The Stochast $\widehat{\widehat{c}}$ analysis helps to account for variability in input variables intoLCA and embodied energy and $\mathrm{CO}_{2}$-eq analysis. The application of the stochastic embodied $\mathrm{CO}_{2}$-eq analysis as demonstrated in this stuÂy can be extended to other building sectors and countries and can form the basis for the development of evidencebased policy formulation since it provides greater information $\theta_{\Omega}$ embodied $\mathrm{CO}_{2}$-eq intensities of building than deterministic approaches.
\end{abstract}

\section{Introduction}

Greenhouse gas (GHG) mitigation is now a central policy of almost all developed economies. Because buildings account for approximately $40-50 \%$ of total emissions in these countries [1,2] such policies focus on emissions' reductions from the built environment through measures such as promoting energy efficiency and the deployment of renewable energy supply (RES) technologies. These measures, however, fail to address the increasingly important role that embodied energy (the energy required to produce a building) plays in building-related emissions, which can represent as much as $40 \%$ of life cycle emissions for residential buildings [3].

Scheckels [4] define the embodied energy of a building as the energy consumed by all the process associated with its production. The embodied $\mathrm{CO}_{2}$-eq of a building can therefore be defined as the equivalent carbon dioxide ( $\mathrm{CO}_{2}$-eq) gas emitted into the atmosphere as a result of all the associated energy used in the production of that building. Equivalent carbon dioxide $\left(\mathrm{CO}_{2} \wedge\right.$-eq) represents the

\footnotetext{
* Corresponding author. Tel.: +353 14023940; fax: +353 14023720.

E-mail address: aidan.duffy@dit.ie (A.P. Duffy).
}

most important anthropogenic energy-related greenhouse gases (GHGs) with the highest environmental impacts. These are: carbon dioxide $-\mathrm{CO}_{2}$; nitrous oxide $-\mathrm{N}_{2} \mathrm{O}$; and methane $-\mathrm{CH}_{4}$ [5]. These emissions are associated with the initial phase of a building's life cycle, preceding emissions resulting from operational energy use and energy used in demolition and recycling.

It is recognized that operational energy analysis has dominated building energy research for many years when compared to embodied energy analysis. It has been shown however, that the energy embodied in buildings is significant when compared to its operational energy use. For example, Yohanis et al. [6] showed that energy initially embodied in a single-storey office building could be as much as $67 \%$ of its operating energy over a 25-year period. Moreover, research carried out by the Commonwealth Scientific and Industrial Research Organisation [7] also shows that embodied energy of a building is a significant multiple of the annual operating energy consumed, ranging from around 10 times for typical dwellings to over 30 times for office buildings. It is also a well established fact that as buildings become more operationally energy efficient, the embodied energy to operational energy ratio increases. Embodied energy and emissions are therefore likely to account for an increasingly large proportion of building-related life cycle $\mathrm{CO}_{2}$-eq emissions in the future.

0378-7788/\$ - see front matter (c) 2011 Published by Elsevier B.V. doi:10.1016/j.enbuild.2011.01.006 
The importance of embodied energy and embodied $\mathrm{CO}_{2}$-eq analysis should therefore not be underestimated when assessing life cycle energy requirements, resource depletion and related environmental impacts.

The development of embodied $\mathrm{CO}_{2}$-eq analysis and life cycle assessment (LCA) has progressed significantly in recent years, and LCA has become a mainstream practice in many industries as evidenced by the development of the ISO 14040 and 14044 Life Cycle Assessment Environmental Standards. However, it is recognized that due to weaknesses in gathering data on product-related energy use and emissions, embodied energy values are probabilistic $[8,9]$. For example: designers and contractors are currently unable to obtain embodied emissions in the products they employ (apart from in exceptional circumstances); and the use of sectoral emissions intensities (derived using input-output ( $\mathrm{C}-\mathrm{O}$ ) techniques) to estimate emissions for a particular product or process is normal practice, although the intensity relates to a wide range of products and processes aggregated into one sector. Despite these uncertainties regarding the applicability of data to the product being analysed, it is noted by commentators (inter alia $[9,10]$ ) that even with the recent methodological improvements, the general approach to estimating embodied emissions and energy remains deterministic, thus obscuring both the uncertainty and true variability in embodied energy and life cycle assessment results.

Best practice in embodied emissions analysis involves a hybrid approach incorporating both process and input-output analysis (inter alia [11-13]). These two approaches rely respectively on process-related data and national sectoral economic data combined with environmental accounts to give emissions per unit monetary output from a sector. For process data, uncertainties arise due to variations in manufacturing processes and supply chains, measurement error and the use of out-of-date data. In the case of input-output data, a significant source of error is due to its highly aggregated nature: for example, construction sector emissions intensity is equally applied to house building and motorway construction. Pacca and Horvath [14] identify that uncertainties can also arise from economic boundary and methodological constraints.

A number of studies have deterministically calculated embodied energy and LCA values for a variety of building types in different countries. For example, Fay et al. [15] have estimated the energy intensity of an Australian residential building to be $1803 \mathrm{GJ}$ while Thormark [16] calculated an embodied energy of $2.9 \mathrm{GJ} / \mathrm{m}^{2}$ for a Swedish apartment. Treloar et al. [17] also estimated the embodied energy of a three storey office building to be $10.7 \mathrm{GJ} / \mathrm{m}^{2}$. Dixit et al. [18] compiled a list showing different deterministic embodied energy values in residential and commercial buildings. Due to the constraints mentioned above, these data may be representative of a very small sample of buildings which do not provide sufficient information for decision makers to identify methods for reducing energy consumption in the building and construction supply chain. If however, the distributions of embodied $\mathrm{CO}_{2}$-eq can be estimated, then decision makers can design targeted policies to reduce the overall emissions in an industry sector or market segment. Understanding the distribution of embodied emissions in the construction sector or segment (for example in the apartment building sector) can therefore be useful in the formulation of effective policies. Furthermore, building designers and contractors will be better placed in terms of having more detailed information on their buildings which will enable them take informed environmental decisions on their designs as well as in their choice of building products and processes.

The main aim of this work is to develop and implement methodologies which measure the nature and extent of uncertainty when estimating embodied $\mathrm{CO}_{2}$-eq emissions in buildings. Specific objectives include:
- the presentation of a stochastic embodied $\mathrm{CO}_{2}$-eq assessment methodology incorporating both process and jnput-output analysis;

- using industry data to estimate the probability distributions of embodied $\mathrm{CO}_{2}$-eq intensities for a particular building sector; and

- an evaluation of the embodied $\mathrm{CO}_{2}$-eq intensities and the uncertainty across a particular building type in Ireland,

The stochastic embodied emissions methodology employed in this study is applicable to any type of structure, sectors other than construction as well as to other countries.

\section{Methodology}

The methodology adopted involves:

- the use of hybrid analysis to develop relationships between input parameters such as product emissions intensities, input-output (I-O) sectoral emissions intensities, disaggregated construction emissions intensities, construction materials employed and construction expenditure;

- an analysis of industry and economic (input-output) data to estimate probability distributions for certain input parameters;

- an application of the model to 7 Irish apartment buildings;

- the use of Monte Carlo simulation to derive probability and cumulative distributions for emissions intensities for the seven apartment buildings; and

- analysis and interpretation of results.

139

Hybrid embodied $\mathrm{CO}_{2}$-eq intensities are calculated where process analysis is used to determine the embodied $\mathrm{CO}_{2}$-eq in the main building materials, sub-sector direct embodied $\mathrm{CO}_{2}^{-}$eq intensities to derive the direct embodied $\mathrm{CO}_{2}$-eq emitted on sife in constructing the buildings, and input-output analysis to estimate the indirect embodied $\mathrm{CO}_{2}$-eq emitted in the construction of the building.

Seven apartment buildings in Dublin are investigated. For each apartment, the stochastic hybrid embodied $\mathrm{CO}_{2}$-eq intensities are evaluated using Monte Carlo analysis by deriving input distributions for the stochastic input variables. A distribution representative of the hybrid embodied $\mathrm{CO}_{2}$-eq distribution of apartment buildings in Ireland is derived by combining the distributions of the seven apartment buildings. This is based on the assumption that the samples are representative of the population of apartment buildings in Ireland. An analysis is then carried out on these distributions including deriving statistical parameters and the level of uncertainty in the results.

\subsection{Stochastic hybrid embodied $\mathrm{CO}_{2}^{-e q}\left(\mathrm{ECO}_{2}^{-}{ }_{\Lambda}^{-e q}\right)$ intensity}

Construction sector $\mathrm{CO}_{2}$-eq emissions can be characterised as direct or indirect. The former are released as a result of activities directly related to construction processes on site (for example: excavation, fit-out, plant operation). The latter are associated with the use of energy in construction-related activities necessary for, but preceding site activities - these activities are 'upstream' of site work in the construction procurement supply chain (for example: energy used to manufacture building materials, excavation of raw aggregate, design team activities). The hybrid embodied $\mathrm{CO}_{2}-$ eq $\left(\mathrm{ECO}_{2}\right.$-eq) intensity can be broken down into three parts and expressed in terms of total grams of embodied $\mathrm{CO}_{2}$-eq per Euro $\left[\mathrm{gCO}_{2}-\mathrm{eq} / €\right]$ of total expenditure. Building materials embodied $\mathrm{CO}_{2}-$ eq intensities are calculated by process analysis, direct embodied $\mathrm{CO}_{2}$-eq emissions on the construction site are evaluated from disaggregated economic data of Irish construction firms and indirect

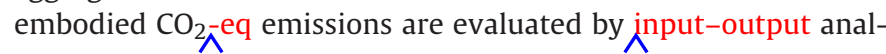


ysis. Mathematically, the Hybrid $\mathrm{ECO}_{2}-\mathrm{eq}$ intensity is expressed as:

Hybrid $\mathrm{ECO}_{2}$-eq intensity

$$
=\frac{\left[\sum_{x=1}^{n} M_{x} e_{x}\right]+\left[i_{i} \sum_{j=1}^{5} S_{j}+\sum_{j=1}^{5} i_{d j} S_{j}\right]}{\sum_{j=1}^{5} S_{j}+C_{p}}
$$

where $M_{x}$ is the mass of building material $x$ [tonnes, $t$ ]; $n$ the number

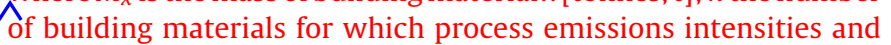
quantities exist; $e_{x}$ the process embodied $\mathrm{CO}_{2}$-eq intensity of building material $x\left[\mathrm{gCO}_{2}-\mathrm{eq} / \mathrm{t}\right] ; i_{i}$ the input-output indirect embodied $\mathrm{CO}_{2}$-eq intensity of construction $\left[\mathrm{gCO}_{2}\right.$-eq/ $\left.€\right]$; $i_{d j}$ the direct embodied $\mathrm{CO}_{2}$-eq intensity of each construction sub-sector $j\left[\mathrm{gCO}_{2}\right.$-eq/€]; $j$ the number of construction sub-sectors; $S_{j}$ the expenditure classified by construction sub-sector, $j$ on activities associated with the construction of the building $[€]$; and $C_{p}$ the total cost of building materials analysed using process $\mathrm{CO}_{2}$-eq intensity inventory [ $€$ ].

The following steps were undertaken in the calculation to avoid double counting of input-output inputs into the model for which process data (associated with building materials) has already been collected:

- the total cost of building materials, $C_{p}$, to which process data were applied was subtracted from the total expenditure extracted from the bill of quantities, therefore the remaining expenditure represented by $\sum_{j=1}^{5} S_{j}$ is only attributed to $\Lambda^{-O}$ inputs;

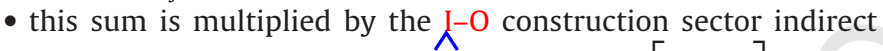
emissions to estimate total indirect emissions $\left[i_{i} \sum_{j=1}^{5} S_{j}\right]$; and

- individual sub-sectoral expenditures, $S_{j}$, are multiplied by the corresponding direct emissions coefficients, $i_{d j}$ and then summed to estimate total direct emissions $\left[\sum_{j=1}^{5} i_{d j} S_{j}\right]$.

\subsubsection{Material process embodied $\mathrm{CO}_{2}$-eq intensities}

According to Goggins et al. [19] the sustainability credentials of construction materials are gaining increasing importance as the environmental impact of the construction industry becomes apparent. Data on the $\mathrm{ECO}_{2}$-eq intensities of building materials however are uncertain. Industry (process) data was therefore used to estimate probability distributions for all process embodied $\mathrm{CO}_{2}$-eq intensities of building materials. Available but limited data of buildings materials process $\mathrm{CO}_{2}$-eq intensities obtained from the Inventory of Carbon and Energy database, ICE v1.6a [20] are fitted into a probability density function using EASYFIT Statistical Application and the distributions ranked according to Kolmogorov-Smirnov goodness of fit from a set of 57 different distributions. Kolmogorov-Smirnov test (K-S test) was preferred to other goodness of best fit tests such as Anderson-Darling goodness of best fit because it is sensitive to differences in both the location and shape of different distributions [21]. It is also an exact test, that is, the chi-square goodness-of-fit test depends on an adequate sample size for the approximations to be valid. Moreover, Anderson-Darling test is only available for a few specific distributions. Using the statistical parameters of the number one ranked fitted distribution, a set of 10,000 random embodied $\mathrm{CO}_{2}$-eq intensities are then generated for each of the building materials and used as input variables for the stochastic modeling. As an example, the embodied $\mathrm{CO}_{2}$-eq intensity probability distribution of insulation is shown in Fig. 1 .

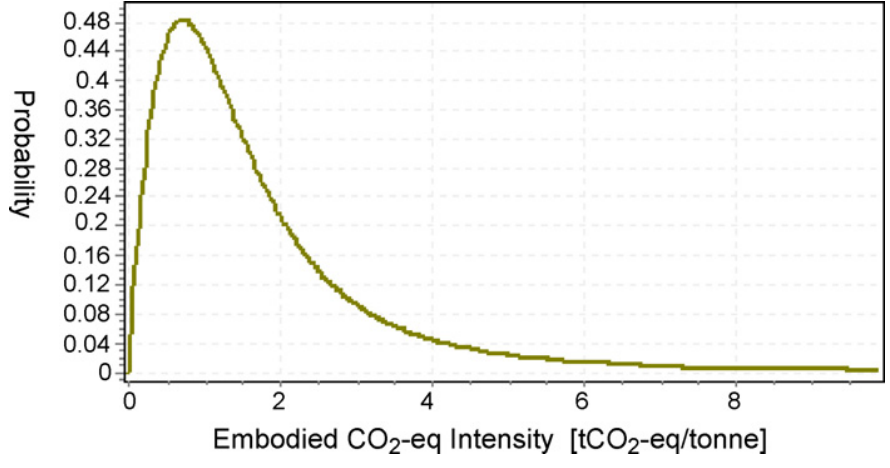

Fig. 1. Embodied $\mathrm{CO}_{2}$-eq intensity distribution of insulation.

Table 1

Common building materials, their embodied $\mathrm{CO}_{2}$-eq distributions and statistical parameters.

\begin{tabular}{lll} 
Building materials & Type of distribution & Distribution parameter \\
\hline Concrete & Dagum function & $k=0.11 ; \alpha=0.4 ; \beta=0.95 ; \gamma=0.03$ \\
Steel & Kumaraswany & $\alpha_{1}=2.1 ; \alpha_{2}=99.0 ; a=0.22 ; b=20$ \\
Insulation & Burr function & $k=1.5 ; \alpha=1.8 ; \beta=1.7 ; \gamma=0$ \\
Timber & Kumaraswany & $\alpha_{1}=0.34 ; \alpha_{2}=1.7 ; a=0.27 ; b=3.9$ \\
Stone & Gamma & $\alpha_{1}=0.32 ; \beta=0.21 ; \gamma=0.06$ \\
Brick & Kumaraswany & $\alpha_{1}=0.28 ; \alpha_{2}=1.7 ; a=0.18 ; b=2.8$ \\
\hline
\end{tabular}

Table 2

Distributions and statistical parameters of the construction sub-sectors.

\begin{tabular}{lll}
\hline $\begin{array}{l}\text { Construction } \\
\text { sub-sectors }\end{array}$ & $\begin{array}{l}\text { Type of } \\
\text { distribution }\end{array}$ & Distribution parameter \\
\hline Ground work & Gen gamma (4P) & $k=1.2 ; \alpha=0.56 ; \beta=6.6 ; \gamma=0.02$ \\
Structural work & Log-logistic & $\alpha=1.1 ; \beta=0.02 ; \gamma=2.4 \times 10^{-6}$ \\
Services & Frechet & $\alpha=1.0 ; \beta=0.02 ; \gamma=0$ \\
Finishes & Dagum & $k=0.73 ; \alpha=1.6 ; \beta=0.39 ; \gamma=0$ \\
Plant operation & Frechet & $\alpha=1.1 ; \beta=11.0 ; \gamma=-2.9$ \\
\hline
\end{tabular}

Table 1 shows some common building materials used in apartment buildings and the number one ranked distribution the process embodied $\mathrm{CO}_{2}$-eq intensities fits onto. In column 3 of Table 1, the statistical parameters used with the distribution type to generate the random embodied $\mathrm{CO}_{2}$-eq intensities are shown.

\subsubsection{Direct sub-sectoral embodied $\mathrm{CO}_{2}$-eq intensities}

Probability distributions are also derived for the direct embodied $\mathrm{CO}_{2}$-eq intensities, $i_{d j}$ of each of the five construction sub-sectors using disaggregated micro energy data collected by the Irish Central Statistics Office in their Census of Building and Construction [22-25] from 2003 to 2006. The sample data from the construction firms was chosen to be representative of the Irish construction sector and methodological notes are available from the Irish Central Statistics Office [26]. 682 firms were sampled in 2003, 628 in 2004, 728 in 2005 and 1291 in 2006. Table 2 shows a summary of the stochastic direct embodied $\mathrm{CO}_{2}$-eq intensity distributions and the statistical parameters of the construction sub-sector which was weighted from 2003 to 2006. It is assumed that all fuel used was diesel since the vast majority of plant and construction machinery in Ireland operates on diesel fuel [24]. Energy expenditure is divided among five construction sub-sectors defined by 'The General Industrial Classification of Economic Activities within the European Communities (NACE rev. 1)'. Construction sub-sectors 1-5 are hereafter referred to as 'Ground Works', 'Structural Work', 'Services', 'Finishes' and Plant Operation' respectively. The sub-sectors are defined in detailed bêow: 


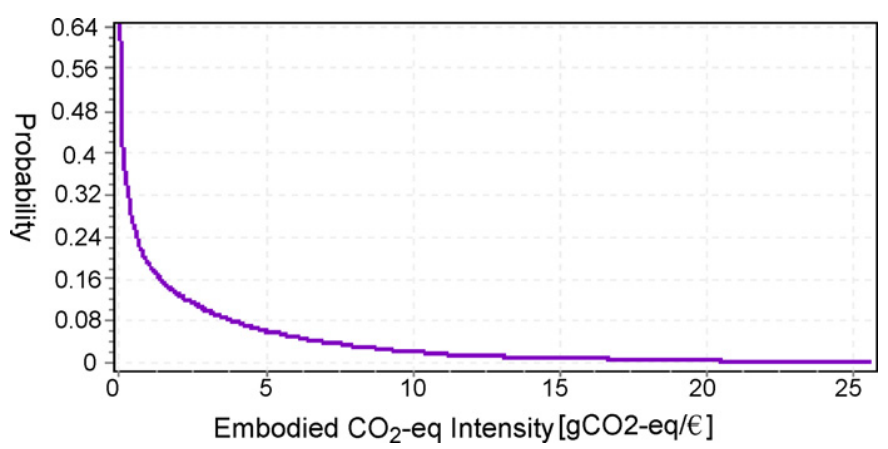

Fig. 2. Direct embodied $\mathrm{CO}_{2}$-eq intensity distribution of construction Sub-Sector 1 : Ground Works, $i_{d 1}$

Ground works: $\quad$ Site preparation, demolition of buildings, earth moving, ground work, drilling and boring, etc. (NACE 45.1) Building of complete constructions or part thereof; civil and structural construction works, etc. (NACE 45.2) Building installation, installation of electrical wiring and fittings, insulation, plumbing and other installations, etc. (NACE 45.3)

Finishes: Building completion, joinery installation, plastering floor and wall, covering, painting, glazing and general fit-out, etc. (NACE 45.4)

Plant operation: Construction plant and equipments, etc. (NACE 45.5)

The equivalent primary energy [GJ] used in each construction sub-sector was calculated by multiplying energy expenditure $[€]$ [22-25], average energy tariffs [GJ/€] derived from the energy balance for Ireland [27] and primary energy factors [GJ/GJ] [28]. The energy intensity for each construction sub-sector is then derived in terms of the energy in GJ per Euro output of each sub-sector. Irish emission factors [g/GJ] [29] and global warming potentials (GWP) of the energy related GHG emissions are then multiplied by the energy intensities to obtain the direct sub-sector embodied $\mathrm{CO}_{2}$-eq intensities $i_{d j}\left[\mathrm{gCO}_{2}\right.$-eq/€]. The GWP of the energy-related GHGs regulated under the Kyoto Protocol over a 100-year timeframe which are relevant to this study are: $\mathrm{CO}_{2}-1 ; \mathrm{N}_{2} \mathrm{O}-298$; and $\mathrm{CH}_{4}-25$. To normalise all data used to the 2005 baseline year in the analysis, energy and construction price indices published by the Central Statistics Office [30] are applied to the average energy tariffs and construction sub-sector output respectively. 2005 was taken as the baseline year because it is the most recent year in which the national supply and use and input-output table has been published for Ireland.

Direct sub-sector $\mathrm{CO}_{2}$-eq intensities $i_{d j}$ of construction activities are treated as stochastic variables. The distributions for the direct sub-sector $\mathrm{CO}_{2}$-eq intensities of the Irish construction sector are derived for each of the five sub-sectors. The distribution and statistical parameters are then used to generate input parameters in the Monte Carlo modeling. As an example, Fig. 2 shows the direct embodied $\mathrm{CO}_{2}$-eq intensity distributions of Sub-Sector 1 -Ground Works. The probability density functions of the distributions obtained for the sub-sectors are presented in Table 3.

Table 3

Construction sub-sector distributions and the probability density functions,

\begin{tabular}{ll}
\hline Distribution & Probability density function \\
\hline 4-parameter generalized gamma & $f(x)=\frac{k(x-\gamma)^{k \alpha-1}}{\beta^{k \alpha} \Gamma(\alpha)} \exp \left(\frac{\gamma-x}{\beta}\right)^{k}$ \\
Log-logistic & $f(x)=\frac{\alpha}{\beta}\left(\frac{x-\gamma}{\beta}\right)^{\alpha-1}\left(1+\left(\frac{x-\gamma}{\beta}\right)^{\alpha}\right)^{-2}$ \\
Frechet & $f(x)=\frac{\alpha}{\beta}\left(\frac{\beta}{x-\gamma}\right)^{\alpha+1} \exp \left(-\left(\frac{\beta}{x-\gamma}\right)^{\alpha}\right)$ \\
Dagum & $f(x)=\frac{a^{\left(\frac{x-\gamma)}{\beta}\right.}{ }^{k \alpha-1}}{\beta\left(1+\left(\frac{x-\gamma}{\beta}\right)^{\alpha}\right)^{k+1}}$ \\
\hline
\end{tabular}

\subsection{Input-output indirect embodied $\mathrm{CO}_{2}$-eq intensity}

Input-output ( $\mathrm{I}-\mathrm{O}$ ) indirect embodied $\mathrm{CO}_{2}$-eq intensity of the construction sector as well as costs associated ${ }^{\text {with }}$ each construction sub-sector $\left(\mathrm{S}_{1}, \mathrm{~S}_{2}, \mathrm{~S}_{3}, \mathrm{~S}_{4}, \mathrm{~S}_{5}\right)$ in the bill of quantities and costs associated with building materials $C_{p}$ are treated as deterministic input variables. Some uncertainties present in $\mathrm{I}-\mathrm{O}$ analysis are outlined by eiolca.net [31] and some of these are addressed in Section 2.2.1. The level of uncertainty in input-output data is however difficult to estimate because the national input-output tables are compiled from a wide range of sources such as national systems of accounts, national economic sources, industry sector reports and statistical data. Lenzen and Dey [32] for instance stated that errors in I-O data depends largely on the error in the respective source data and estimated it to be in the region of $20 \%$. The cost associated with energy use in the construction sub-sector and process analysis associated costs (building material costs) are used as deterministic input variables because they are assumed to be constant and are derived from standard construction industry approved costs of buildings material and construction activities.

Indirect $\mathrm{I}-\mathrm{O}$ emissions are emissions arising from energy use not directly related to on-site construction but upstream of onsite construction and are calculated using $\mathrm{I}-\mathrm{O}$ analysis. These were estimated using data from the Irish national $-O$ tables [33] which are compiled using data from national accounts as well as other national economic sources to show economic transactions between all product sectors of the national economy. The input coefficients of the economy-wide $\mathrm{I}-\mathrm{O}$ tables are used to derive indirect $\mathrm{I}-\mathrm{O}$ emissions intensities in the construction sector. This methodology is widely used and described in literature (see inter alia Bullard et al. [34], Lenzen and Dey [32] and Strømman and Solli [35]). In summary, the approach involves using the 2005 Irish I-O tables [33], average energy tariffs [27] and primary energy factors [28] to determine total $\mathrm{I}-\mathrm{O}$ and direct $\mathrm{I}-\mathrm{O}$ energy intensities per unit monetary value of construction sector output. The indirect $-O$ energy intensity is calculated as the difference between the total $\mathrm{X}-\mathrm{O}$ and direct $-\mathrm{O}$ energy intensities and is then converted to indirect $\mathrm{I}-\mathrm{O}$ emissions intensity using the Irish emissions factors [29]. The direct requirement coefficient matrix of the Irish $\mathrm{I}-\mathrm{O}$ tables was used to evaluate the direct $\mathrm{I}-\mathrm{O}$ energy intensity and the Leontief inverse matrix used to calculate the total domestic energy intensity $[13,36]$.

\subsubsection{Limitations and the treatment of errors in $-\mathrm{O}$ analysis}

I-O analysis is known to suffer from well-documented limitations such as assumptions of homogeneity and proportionality [37]. For example, the proportionality assumption presumes that the inputs to each sector are proportional to their outputs so that if the output of a sector increases or decreases, then the consumption of intermediaries and primary inputs of that sector will also increase or decrease proportionally. In reality, there is not always a direct proportionality between activity and energy use. However, economies of scale should act to reduce marginal energy consumption. Homogeneity assumption proposes that each sector produces a single output using identical inputs and processes; however, this is obviously not the case with each sector containing many different products and services. Heterogeneity therefore occurs within the sector because of the aggregation of different production processes and products. Furthermore, $-O$ analysis assumes the uniform conversion of economic data into physical quantities (energy and emissions in this case) within a sector. For example, economic data are converted to energy consumed using national average energy tariffs, although such tariffs will vary across different industries.

This paper attempts to address some of these limitations. Disaggregation coefficients are used to disaggregate the energy supply sectors thus mitigating errors associated with the assumptions of 
homogeneity and uniform conversion [38]. Another limitation of $\mathrm{I}^{-\mathrm{O}}$ analysis is the aggregation of many different products into one sector in the national $\mathrm{O}-\mathrm{O}$ tables [39]. This reduces applicability of $\mathrm{I}-\mathrm{O}$ derived embodied $\mathrm{CO}_{2}$-eq intensities to a specific product or product sector. In Ireland, the national I-O table contains three aggregated energy supply sectors, namely:

i. Coal, Peat, Crude Oil and Metal Ore Extraction;

ii. Petroleum and Other Manufacturing Products; and

iii. Electricity and Gas,

Some energy supply sectors are aggregated together either with non-energy supply sectors or other energy supply sectors. For example, the 'Petroleum and Other Manufacturing' sector is an aggregation of an energy supply sector, Petroleum' and non-energy supply sector 'Other Manufacturing'. $\wedge$ Therefore, to address the aggregation problem, disaggregation coefficients are introduced to separate the energy supply sectors into individual energy sources to which emissions factors can be applied. An analysis of the disaggregation of the energy supply sectors in Ireland and its application to embodied emissions was carried out by Acquaye and Duffy [38]. The use of the disaggregation constants has a two-fold advantage. Firstly, non-energy supply sectors are eliminated from the analysis. Secondly, it enables individual primary energy factors and specific energy tariffs to be used instead of average values for two or more aggregated energy supply sectors (for example, for the aggregated electricity and gas sector).

A further development of $\mathrm{I}-\mathrm{O}$ analysis and its application to the embodied $\mathrm{CO}_{2}$-eq analysis of buildings relates to the system boundary in the I-O analysis. Direct Requirement and Leontief Inverse $\mathrm{I}-\mathrm{O}$ coefficients for Ireland were derived for domestic product flows only, omitting energy inputs into imported products and services. For example, EuroStat [40] states that in order to account for the whole life energy use of a product using $\mathrm{I}^{-O}$ analysis, the energy used to produce imported inputs should also be included in such an analysis. As such a methodology set out in the EuroStat European System of Accounts I-O Manual [40] is applied to re-derive the Irish direct and Leontief coefficients which are used to calculate the $\mathrm{I}-\mathrm{O}$ indirect $\mathrm{CO}_{2}$-eq emissions. The estimation of the addition of energy inputs into imported construction sector goods and services is important in an open economy such as Ireland's [41] and provides greater information for decision making by designers and policy makers by considering total global impacts. Furthermore, given that approximately 56\% of Irish imports are from the EU [42] an understanding of the sources of emissions are important from an EU policy perspective.

\subsection{Case studies}

The seven apartment buildings are all located in Ireland. They comprise concrete strip foundations and ground floor slabs with block-work rising elements, timber floors and roof structures. External finishes included brickwork and render, double-glazed timber-framed windows and concrete roof tiles. Internal finishes included timber stud partitions, plasterwork, tiling, fitted kitchens and painting. Further details are presented in Table 4.

\section{Results}

\subsection{Hybrid embodied $\mathrm{CO}_{2} \wedge^{-e q}$ intensity distributions}

For each apartment building, 10,000 Monte Carlo simulations were undertaken and the results (hybrid $\mathrm{ECO}_{2}$-eq intensities) were plotted on a scatter diagram. The scatter diagram in Fig. 3 illustrates the variations that occur in the stochastically derived hybrid $\mathrm{ECO}_{2}-$
Table 4

Description of apartment buildings used in the case studies.

\begin{tabular}{|c|c|}
\hline Apartments & Description of apartment buildings \\
\hline Apartment 1 & $\begin{array}{l}\text { Concrete piled foundation, reinforced concrete frame with } \\
\text { infill } 215 \mathrm{~mm} \text { block-work; } 320 \mathrm{~mm} \text { thick reinforced concrete } \\
\text { slab with } 400 \mathrm{~mm} \times 600 \mathrm{~mm} \text { reinforced concrete columns on } \\
9 \mathrm{~m} \times 9 \mathrm{~m} \text { grids. External finishes included brickwork and } \\
\text { render, double-glazed timber-framed windows, thermafloor } \\
\text { insulation and concrete roof tiles. Internal finishes included } \\
\text { timber stud partitions, plasterwork and painting. }\end{array}$ \\
\hline Apartment 2 & $\begin{array}{l}\text { Reinforced concrete frame with minor structural steel to } \\
\text { roof; } 300 \mathrm{~mm} \text { thick reinforced concrete slab with } \\
400 \mathrm{~mm} \times 400 \mathrm{~mm} \text { reinforced concrete columns on } 8 \mathrm{~m} \times 8 \mathrm{~m} \\
\text { grids. Thermafloor insulation and external finishes include } \\
\text { plaster work with gloss paint to wood work. Roof work } \\
\text { consists of mastic asphalt roofing with rigid sheet covering } \\
\text { and decking. Extensive mechanical installations made up of } \\
\text { waste, water, gas, heating, HVAC, and lift installations. }\end{array}$ \\
\hline Apartment 3 & $\begin{array}{l}\text { Reinforced concrete substructure, block work external walls } \\
440 \times 215 \times 100 \text {, concrete work in concrete frame structure, } \\
\text { woodwork and precast pre-stressed concrete work for stairs, } \\
\text { structural steel work fabricated members, internal walls } \\
\text { partitioned with softwood and thermafloor insulation. }\end{array}$ \\
\hline Apartment 4 & $\begin{array}{l}\text { Reinforced concrete substructure with reinforced concrete } \\
\text { in situ concrete frame, fabricated members steel work, } \\
\text { concrete work stairs } 1.2 \mathrm{~m} \text { wide, block work internal walls } \\
100 \times 215 \times 440 \text {, in situ concrete floors and slabs exceeding } \\
150 \mathrm{~mm} \text { reinforced and thermafloor insulation. }\end{array}$ \\
\hline Apartment 5 & $\begin{array}{l}\text { Structural steel work with fabricated members, brickwork } \\
\text { and block work internal walls with concrete blocks } \\
100 \times 215 \times 440 \text {. In-situ concrete floors slabs exceeding } \\
150 \mathrm{~mm} \text { thick and precast concrete } 200 \mathrm{~mm} \text { thick with span } \\
>5.00 \mathrm{~m} \text { and }<7.00 \mathrm{~m} \text {. Thermafloor insulation and structural } \\
\text { steel work roof } 254 \times 146 \times 37 \mathrm{~kg} / \mathrm{m} \text { Universal Beam. }\end{array}$ \\
\hline Apartment 6 & $\begin{array}{l}\text { Reinforced concrete substructure, brickwork and concrete } \\
\text { work size } 440 \times 215 \times 100 \text {, floor insulation laid to underside } \\
\text { of floor, in situ concrete floor exceeding } 150 \mathrm{~mm} \text { thick. } \\
\text { Concrete walls consist of reinforced in situ concrete with } \\
\text { thickness not exceeding } 0.20 \mathrm{~m}^{2} \text {. Concrete screed floor } \\
75 \mathrm{~mm} \text { thick with fabric reinforcement. }\end{array}$ \\
\hline Apartment 7 & $\begin{array}{l}\text { Reinforced concrete substructure, brickwork and concrete } \\
\text { work size } 440 \times 215 \times 100 \text {; brick and block work external } \\
\text { walls, coping to parapet } 560 \times 150 \text {. Precast concrete lintels, } \\
100 \times 65 \mathrm{~mm} \text {, Insulation board } 100 \mathrm{~mm} \text { thick, structural steel } \\
\text { work } 50 \times 90 \times 10 \mathrm{~kg} / \mathrm{m} \text { stainless steel. Carcassing roof with } \\
\text { insulation }\end{array}$ \\
\hline
\end{tabular}

eq intensities of Apartment 1. Scatter diagrams for Apartments 2-7 are presented in the AppendixBAppendix.

Fig. 4 is an illustration the $\mathrm{ECO}_{2}$-eq intensity probability distributions of each of the apartment buildings analysed in the study. Each distribution shows the $\mathrm{ECO}_{2}$-eq intensity probability variations relating to the scatter pots in Fig. 3 and the AppendixBAppendix.

Fig. 5 shows the scatter plot of the combined seven apartment buildings representing 70,000 Monte Carlo simulated results and assumed to be the average for the apartment building sector in Ireland. It shows the dispersion in embodied emissions intensities of the apartment buildings due to the variability in input parameters such as emission intensities of building materials.

The average hybrid $\mathrm{ECO}_{2}$-eq intensity distribution for apartment buildings in Ireland shown in Fig. 6 was obtained by combining the individual distributions of the seven apartment buildings and also represents the combined $\mathrm{ECO}_{2}$-eq intensity scatter plots in Fig. 5. The distribution can be characterised as a Wakeby distribution with five parameters: $\beta=1.4 \times 10^{2}, \gamma=1.3 \times 10^{2}$ and $\delta=0.77$ are shape parameters while $\zeta=0$ and $\alpha=1.5 \times 10^{5}$ are location parameters.

A general quantile function for a Wakeby Distribution is given by Eq. (2) below:

$x(F)=\zeta+\frac{\alpha}{\beta}\left(1-(1-F)^{\beta}\right)-\frac{\gamma}{\delta}\left(1-(1-F)^{-\delta}\right)$ 


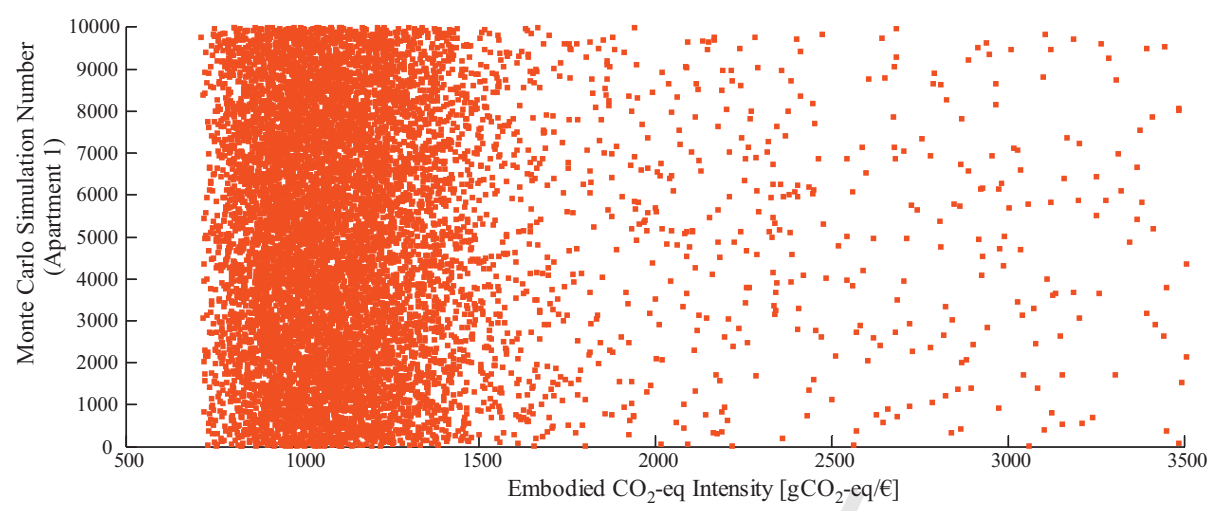

Fig. 3. Scatter diagram of 10,000 simulated $\mathrm{ECO}_{2} \wedge$-eq intensity results for Apartment Building 1 .

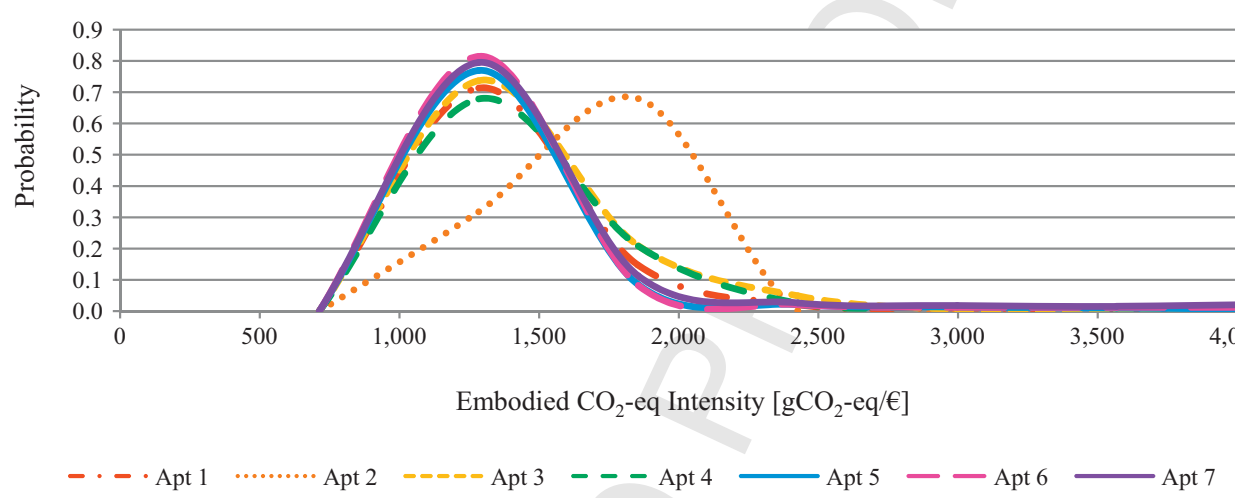

Fig. 4. Hybrid embodied $\mathrm{CO}_{2}$-eq intensity probability distributions of the 7 apartment buildings.

Hence, the quantile function describing the derived average distribution for apartment buildings in Ireland is given by Eq. (3) below:

$x(F)=1071\left(1-(1-F)^{1.4 \times 10^{2}}\right)-168\left(1-(1-F)^{-0.77}\right)$

The $\mathrm{ECO}_{2}$-eq intensity distribution in Fig. 6 was derived using 100 class intervals with a bin or class size of $570 \mathrm{gCO}_{2}-\mathrm{eq} / €$. The mean $\mathrm{ECO}_{2}$-eq intensity was found to be $1636 \mathrm{gCO}_{2}$-eq/€ while the median was $1127 \mathrm{gCO}_{2}$-eq/€. This can be interpreted to imply that an 'average' design of Irish apartment buildings built in 2005 will result in the emissions of $1636 \mathrm{gCO}_{2}$-eq/€. This is based on the assumption that the building samples analysed are representative of the population of apartment buildings in Ireland. Based on a class size of $570 \mathrm{gCO}_{2}$-eq/€ (representing 100 class intervals) used in the distribution, the likeliest embodied $\mathrm{CO}_{2}$-eq intensity of an apartment building is $1325 \mathrm{gCO}_{2}$-eq/€ with a probability of $69 \%$.

Using the principle that the uncertainty of a measured result can be taken to represent the estimated standard deviation [43]

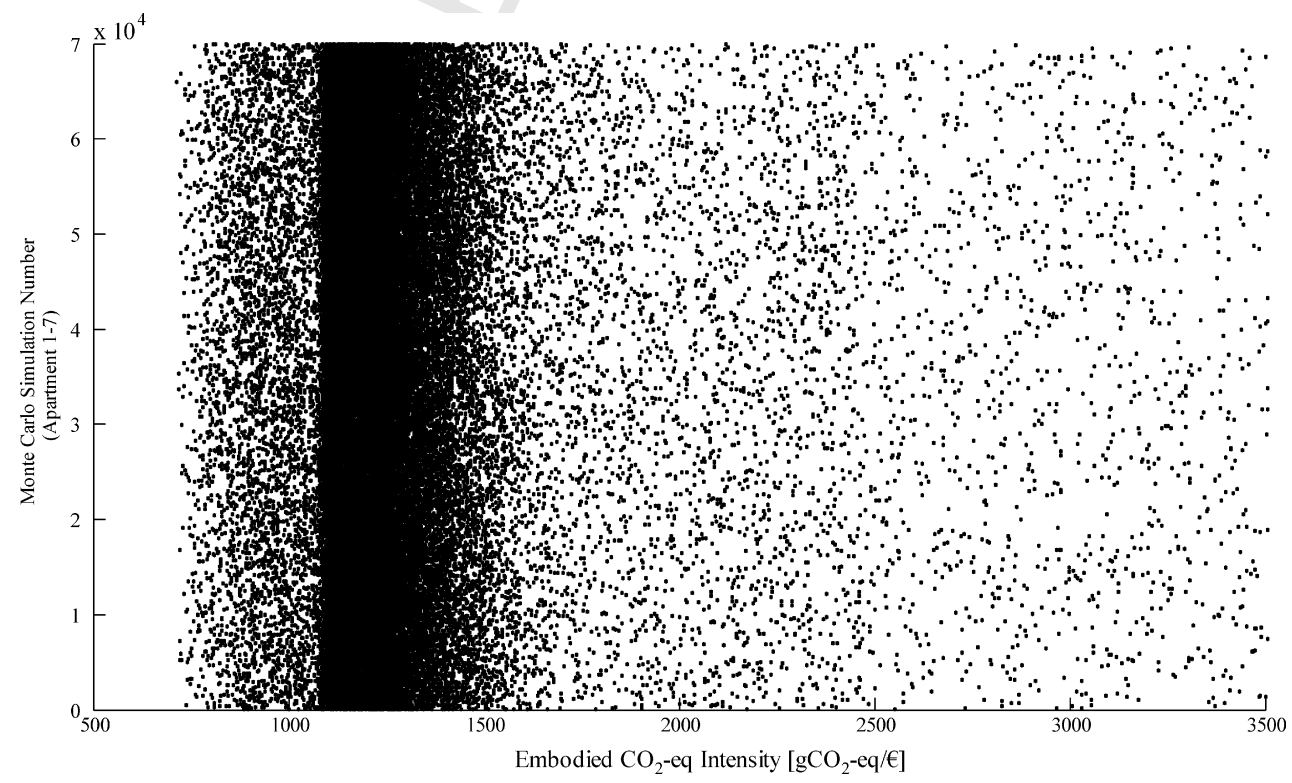

Fig. 5. Scatter diagram of 70,000 simulated $\mathrm{ECO}_{2}$-eq intensity results for apartment buildings in Ireland.

Please cite this article in press as: A.A. Acquaye, et al., Stochastic hybrid embodied $\mathrm{CO}_{2}$-eq analysis: An application to the Irish apartment building sector, Energy Buildings (2011), doi:10.1016/j.enbuild.2011.01.006 


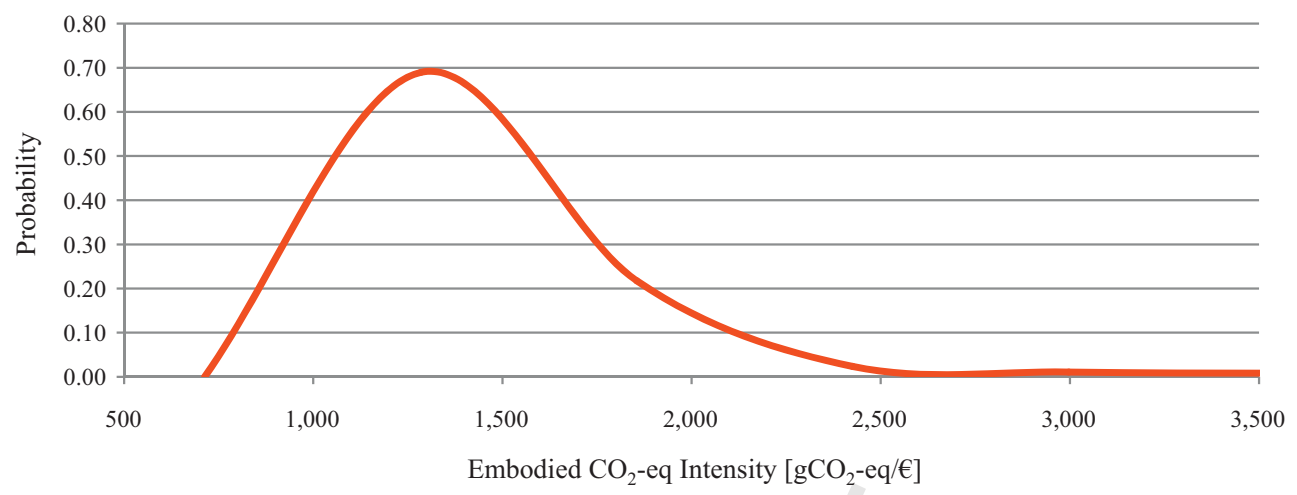

Fig. 6. Embodied $\mathrm{CO}_{2}$-eq intensity probability distribution of apartment buildings in Ireland.

the uncertainty associated with the stochastic $\mathrm{ECO}_{2}$-eq intensity distribution can be evaluated. It is therefore estimated that the mean of the stochastic distribution of $\mathrm{ECO}_{2}$-eq intensity across the apartment building sector is $1636 \mathrm{gCO}_{2}$-eq $€ €$ with an uncertainty of $73 \mathrm{gCO}_{2}$-eq/€. An embodied $\mathrm{CO}_{2}-$ eq intensity of $73 \mathrm{gCO}_{2}$-eq/€ was estimated as the standard deviation of the Wakeby derived average distribution of apartment buildings in Ireland after 70,000 stochastic simulations. It can therefore be assumed that an embodied $\mathrm{CO}_{2}$-eq intensity calculated for an apartment building in Ireland would have an uncertainty of $73 \mathrm{gCO}_{2}$-eq/€ It is however recognized that the addition of stochastic analysis for $\mathrm{I}-\mathrm{O}$ indirect emissions will change the level of uncertainty in the overall results. This is because Lenzen and Dey (2000) reported that the estimated inherent error and variability in I-O data is in the region of $20 \%$.

The cumulative hybrid $\mathrm{ECO}_{2}-\mathrm{eq}$ intensity probability distribution of apartment buildings in Ireland is presented in Fig. 7. The median (50th percentile) and the 90th percentile are respectively $1127 \mathrm{gCO}_{2}$-eq/€ and $1723 \mathrm{gCO}_{2}$-eq/€. This can be interpreted to mean that apartment buiddings with embodied $\mathrm{CO}_{2}$-eq intensity greater or equal to $1723 \mathrm{gCO}_{2}$-eq/€ are in the top $10 \%$ of apartment buildings with the highest embodied emissions impacts in Ireland.

\section{Discussion}

In Fig. 4, the hybrid $\mathrm{ECO}_{2}$-eq intensity distributions of the individual apartment buildings can be observed. The differences in the distribution of Apartment 2 relative to the others can be attributed to two factors: firstly, Apartment 2 contained much greater quantities of mechanical and electrical services, the process probability density function for which resulted in negative skewing of the distribution for the overall building; secondly, indirect I-O data displaced a greater proportion of non-services-related process data, thus excluding more positively skewed distributions from the result. The importance of using stochastic techniques in $\mathrm{ECO}_{2}$-eq intensity analysis is seen in the ability of the model to capture the variability in the embodied emissions in each building. For the combined hybrid $\mathrm{ECO}_{2}$-eq intensity distribution, the uncertainty measured as the standard deviation of the distribution is estimated to be $73 \mathrm{gCO}_{2}$-eq/€. The uncertainty measured across the apartment building sector can therefore be factored into any calculation to account for any variability.

Obtaining the combined probability distribution represents an important step forward if embodied emissions policy measures are to be formulated. This helps both policymakers to formulate a basis for providing embodied $\mathrm{CO}_{2}$-eq intensity information in different sectors, and building designers to make informed decision on material selection based on their embodied $\mathrm{CO}_{2} \wedge$-eq intensities (see Venkatarama Reddy and Jagadish [44]).

The combined $\mathrm{ECO}_{2}^{-\mathrm{eq}}$ intensity probability distributions yielded a Wakeby distribution. While this was derived from analysing seven apartment buildings because of limited data, the shape should remain the same because of representative variation (that is, similarity in construction methods, design, materials used, etc.) when it is updated with new information and data. To assess the basis of this assumption, a sensitivity analysis is carried out using the derived $\mathrm{ECO}_{2}$-eq intensity cumulative distribution in Fig. 7. The sensitivity analysis is undertaken based on the premise that despite using only seven buildings as case studies, statistical parameters would not significantly change if large numbers of buildings were sampled. Hence a comparison is made between the cumulative distributions derived from the seven buildings and those derived from a much more limited number of buildings ( 5 and 6 apartment buildings represented by Apartments 1-5 and Apartments 1-6 respectively). As can be observed in Fig. 8, there are marginal differences between the cumulative distribution for the 5 apartment buildings (median: $1.06 \%$; 90 th percentile: $0.08 \%$; and

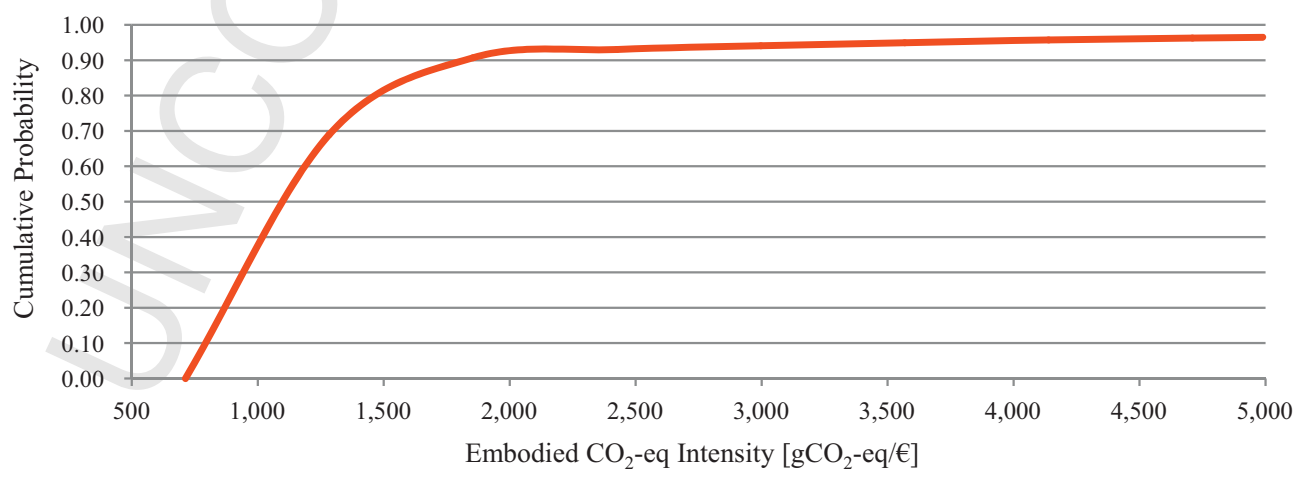

Fig. 7. Embodied $\mathrm{CO}_{2}$-eq intensity cumulative probability distribution of apartment buildings in Ireland. 


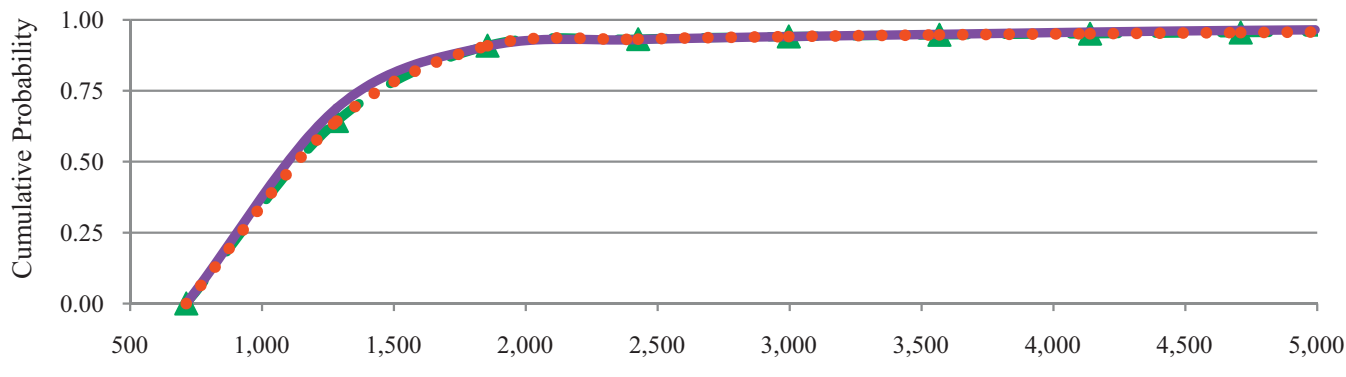

Embodied $\mathrm{CO}_{2}$-eq Intensity $\left[\mathrm{gCO}_{2}\right.$-eq/€ $]$

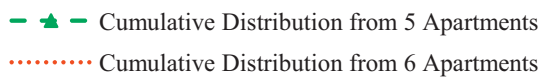

Derived Cumulative Distribution of Apartment Sector

Fig. 8. Sensitivity analysis of the cumulative embodied $\mathrm{CO}_{2}$-eq intensities for different sample size.

mean: $5.04 \%$ ) and that for 6 apartment buildings (median: $0.45 \%$; 90th percentile: $0.08 \%$; and mean: $2.5 \%$ ) when compared to the average of the apartment building sector ( 7 buildings used in this study). While the reasoning behind the sensitivity analysis of $\mathrm{ECO}_{2}-$ eq intensity distribution based on the number of cases analysed $\hat{s}$ valid, for it to be statistically rigorous, a much larger sample size is required, especially if the distributions are to be used to inform policy making.

\section{Conclusions}

This paper proposes a stochastic approach to estimating embodied emissions and, by way of example, applies it to an Irish case study of seven apartment buildings. Greater methodological and informational benefits are derived from the stochastic hybrid $\mathrm{ECO}_{2}$-eq intensity analysis of buildings compared to deterministic analysis. The stochastic $\mathrm{ECO}_{2}$-eq intensity employed integrates the accuracy of process analysis and the system boundary completeness of $-\mathrm{O}$ analysis while providing a solution to the variability that exist in the $\mathrm{ECO}_{2}$-eq intensity data sets. Stochastic analysis also helps to establish the relationship between the $\mathrm{ECO}_{2}$-eq intensity of apartment buildings and the likelihood of obtaining a particular $\mathrm{ECO}_{2}$-eq intensity value. This can provide useful information if embodied $\mathrm{CO}_{2}$-eq standards and regulatory measures are to be formulated. A Wakeby distribution with known parameters and uncertainty was derived for the embodied $\mathrm{CO}_{2}$-eq intensities of apartment buildings in Ireland. Such a stochastic distribution with known parameters provides more useful information to building designers and policy makers. The stochastic embodied emissions methodology employed in this study is applicable to any type of structure, sectors other than construction as well as to other countries.

\section{Acknowledgements}

The authors would like to thank Dr Patrick Quill of the Central Statistics Office in Dublin, Ireland for his advice on the National Supply and Use and Input-Output Tables. The authors also extended their appreciation to Brid Fitzpatrick of the Central Statistics Office in Cork, Ireland for facilitating access to the micro data on Census of Building and Construction.

\section{Appendix A. Supplementary data}

Supplementary data associated with this article can be found, in the online version, at doi:10.1016/j.enbuild.2011.01.006.

\section{References}

Q3 559

[1] S. Sorensen, The Sustainable Network: The Accidental Answer for a Troubled Planet, first ed., O’Reilly Media, Inc, Sebastopol, CA 95472, 2010.

[2] M. Dowden, Climate Change and Sustainable Development: Law, Policy and Practice, EG Books, 2008.

[3] T.Y. Chen, J. Burnett, C.K. Chau, Analysis of embodied energy use in the residential building of Hong Kong, Energy 26 (4) (2001) 323-340.

[4] P. Scheckels, The Home Energy Diet: How to Save Money by Making Your Home Energy Smart, New Society Publishers, 2005.

[5] Intergovernmental Panel on Climate Change, I., Fourth Assessment Report (AR4): Climate Change 2007 Synthesis Report 2007.

[6] Y.G. Yohanis, B. Norton, Life-cycle operatiofil and embodied energy for a generic single-storey office building in the UK, Energy 27 (1) (2002) 77-92.

[7] Commonwealth Scientific and Industrial Research Organisation, $C$ S Sustainable Built Environment: Embodied Energy, 2006.

[8] G.F. Menzies, S. Turan, P.F.G. Banfî, Life-cycle assessment and embodied energy: a review, Proceedings of the Institution of Civil Engineers, Construction Materials 160 (2007) $135-143$

[9] $\mathrm{S}$. Shipworth, A stochastic framework for embodied greenhouse gas emissions modelling of construction materials, Building Research \& Information 30 (1) (2002) 16-24.

[10] L. Shih-Chi, M. Hwong-wen, L. Shang-Lien, Quantifying and reducing uncertainty in life cycle assessment using the Bayesian Monte Carlo method, Science of the Total Environment 340 (2005) 23-33.

[11] S. Joshi, Product environmental life-cycle assessment using input-output techniques, Journal of Industrial Ecology 3 (2-3) (1999) 95-120.

[12] R.H. Crawford, Validation of the use of input-output data for embodied energy analysis of the Australian construction industry, Journal of Construction Research 6 (1) (2005) 71-90.

[13] G.J. Treloar, Extracting embodied energy paths from input-output tables: towards an input-output-based hybrid energy analysis method, Economic Systems Research 9 (4) (1997) 375-391.

[14] S. Pacca, A. Horvath, Greenhouse gas emissions from building and operating electric power plants in the upper Colorado river basin, Environmental Science and Technology, ACS 36 (14) (2002) 3194-3200.

[15] R. Fay, G. Treloar, U. Iyer-Raniga, Life-cycle energy analysis of buildings: a case study, Building Research and Information 28 (2000) 31-41.

[16] C. Thormark, The effect of material choice on the total energy need and recycling potential of a building, Building and Environment 41 (8) (2006) 1019-1026.

[17] G.J. Treloar, P.E.D. Love, O.F. Olusegun, Improving the reliability of embodied energy methods for projects life-cycle decision making, Logistics Information Management 14 (5-6) (2001) 303-317.

[18] M.K. Dixit, et al., Identification of parameters for embodied energy measurement: a literature review, Energy and Buildings 42 (8) (2010) 1238-1247.

[19] J. Gogghms, T. Keane, A. Kelly, The assessment of embodied energy in typica reinforced concrete building structures in Ireland, Energy and Buildings 42 (5) (2010) 735-744.

[20] Sustainable Energy Research Group, in: P.G.H.a.C. Jones (Ed.), Inventory of Carbon and Energy, University of Bath, United Kingdom, 2008.

[21] V.N. Huynh, et al., Integrated Uncertainty Management and Applications, Springer, 2010.

[22] Central Statistics Office 2003 , Census of building and construction Dublin Ireland, 2005.

[23] Central Statistics office $\lambda^{2004 \text {, Census of building and construction }} \lambda^{\text {Dublim, }}$ 24) Centrd Statistics office 2005 , Census of building and construction Dublin,
treland 2007.

[25] Centrd Statistics office $\lambda^{2006}$, Census of building and construction $\lambda^{\text {Dublin, }}$ 6] Centratistic Office, Background Notes to Census of Building and Construction Methodology, 个eland 2008; Available from: http://www.cso.ie/ 
G Model

ENB 3101 1-9

A.A. Acquaye et al. / Energy and Buildings $x x x(2011) x x x-x x x$

9

620

surveysandmethodologies/surveys/census_of_building_and_construc_ methodology.htm.

[27] Sustainable Energy Authority of Ireland, Energy Balance by Energy Supply and Consumption, Year and Fuel Type, Dublin, Ireland, 2009.

[28] Sustainable Energy Authority of Ireland, $1990 \Delta 006$ Energy Statistics for Ireland Cork, Ireland 2007.

[29] Sustainable Energy Authority of Ireland, Emissions Calculator-Version 5. Renewable Energy Information Office 2003

[30] Central Statistics Office, Consumer Price Index 2009.

[31] eiolca.net, Economic Aput-Output Life Cycle Assessment: Assumptions, Uncertainty, and other Considerations with the EIO-LCA Method, 2010.

[32] M. Lenten, C. Dey, Truncation error in embodied energy analyses bf basic iron and steel products, Energy 25 (6) (2000) 577-585

[33] Central Statistics Office 2005, Supply and Use and Input Output Tables for Ireland Dublin, Ireland 2009 .

[34] C.W. BAllard, P.S. Pence), D.A. Pilate, Net energy analysis: handbook for combinning process and input-output analysis, Resources and Energy 1 (3) (1978) 267-313.

[35] A.H. Strømman, C. Solli, Applying Leontief's price model to estimate missing elements in hybrid life cycle inventories, Journal of Industrial Ecology 12 (1) (2008) 26-33.
[36] R.E. Miller, P.D. Blair, Input-Output Analysis: Foundations and Extensions, Prentice-Hall, Englewood Cliffs, NJ, 1985.

[37] C. Hendrickson, A. Horvath, S. Josh, Economic input-output models for environmental life-cycle assessment, Environmental Science \& Technology Policy Analysis 32 (7) (1998) 184-191.

[38] A.A. Acquaye, A.P. Duffy, Input-output analysis of Irish construction sector greenhouse gas emissions, Building and Environment 45 (3) (2010) 784-791.

[39] I. Mongelli, S. Sub, G. Huppes, A Structure comparison of two approaches to LCA inventory data, based on the MIET and ETH databases (10 pp), The International Journal of Life Cycle Assessment 10 (5) (2005) 317-324.

[40] EuroStat, The ESA 95 Input-Output Manual - Compilation and Analysis 2002.

[41] Swedish Chamber of Commerce Ireland, Spotlight Sweden, SCCI News 2006.

[42] Central Statistics Office, Ireland and the EU, 1973-2003: Economic and Social Change Dublin, Ireland, 2004.

[43] The National Institute 6 Standards and Technology, Guidelines for Evaluating and Expressing the Uncertainty of NIST Measurement Results, in NIST Technical Note 1297, 1994.

[44] B.V. Venkatarama ReAdy, K.S. Jagadish, Embodied energy of common and alternative building materials and technologies, Energy and Buildings 35 (2) (2003) 129-137.

640
64
642
643
644
645
646
647
648
649
650
65
65
653
654
655
65
65
658
65
660

Please cite this article in press as: A.A. Acquaye, et al., Stochastic hybrid embodied $\mathrm{CO}_{2}$-eq analysis: An application to the Irish apartment building sector, Energy Buildings (2011), doi:10.1016/j.enbuild.2011.01.006 